\title{
The New NSF Requirement for Broadening Participation in Computing (BPC) Plans
}

\author{
Tracy Camp \\ Dept. of Computer Science \\ Colorado School of Mines \\ Golden, CO, USA \\ tcamp@mines.edu \\ Linda J. Sax \\ UCLA \\ 3045 Moore Hall \\ Los Angeles, CA, USA \\ lsax@ucla.edu
}

\section{Community Advice and Resources}

\author{
Wendy DuBow \\ NCWIT \\ University of Colorado \\ Boulder, CO, USA \\ wendy.dubow@ncwit.org \\ Valerie Taylor \\ CMD-IT \\ 2130 Harvey Mitchell Pkwy South \\ College Station, TX, USA \\ taylor@cmd-it.org
}

\author{
Diane Levitt \\ Cornell Tech \\ 2 West Loop Road \\ New York, NY, USA \\ diane.levitt@cornell.edu \\ Colleen Lewis \\ (Moderator) \\ Harvey Mudd College \\ Claremont, CA, USA \\ lewis@cs.hmc.edu
}

\begin{abstract}
The CISE directorate of the NSF is rolling out a requirement that all NSF grants include a Broadening Participation in Computing (BPC) plan (www.nsf.gov/cise/bpc/). This has the potential to drive important institutional change across CS departments in the U.S. This panel of BPC experts will offer their perspectives on meaningful BPC activities, talk about existing BPC programs, and share BPC-related resources that can help PIs and departments craft high-quality BPC plans. The panelists will offer contrasting perspectives on topics such as K-12 outreach, the allocation of department funds for BPC, faculty engagement, and first steps departments should take. Ultimately, NSF review panels made up of CISE community members will evaluate BPC plans, but we hope to spark productive conversations in the interest of fostering institutional change to achieve the social imperative of BPC.
\end{abstract}

\section{KEYWORDS}

Broadening Participation in Computing; inclusive teaching; culture change

\section{ACM Reference format:}

Tracy Camp, Wendy DuBow, Diane Levitt, Linda Sax, Valerie Taylor and Colleen Lewis. 2019. The New NSF Requirement for Broadening Participation in Computing (BPC) Plans: Community Advice and Resources. In Proceedings of the 50th ACM Technical Symposium on Computer Science Education (SIGCSE'19). Feb. 27-Mar.2, 2019, Minneapolis, MN, USA. ACM, New York, NY, 2 pages. https://doi.org/10.1145/3287324.3287332

Permission to make digital or hard copies of part or all of this work for personal or classroom use is granted without fee provided that copies are not made or distributed for profit or commercial advantage and that copies bear this notice and the full citation on the first page. Copyrights for third-party components of this work must be honored. For all other uses, contact the owner/author(s). SIGCSE '19, February 27-March 2, 2019, Minneapolis, MN, USA

(C) 2019 Copyright is held by the owner/author(s)

ACM ISBN 978-1-4503-5890-3/19/02.

https://doi.org/10.1145/3287324.3287332

\section{Summary}

The On July 3, 2017, the Computer \& Information Science \& Engineering (CISE) directorate at the US National Science Foundation (NSF) released a Dear Colleague Letter (NSF 17-110; www.nsf.gov/pubs/2017/nsf17110/nsf17110.jsp) with a new set of initiatives for Broadening Participation in Computing (BPC). One component is that "all CISE PIs will be strongly encouraged to include meaningful BPC plans in the Broader Impacts section of submitted proposals, starting with deadlines in fall 2017."

"CISE recognizes that BPC will require an array of long-term, sustained efforts and that efforts to broaden participation must be innovative, varied, and welcoming of multiple pathways that eliminate or overcome barriers." (NSF 17-110). Each of our panelists wear multiple hats. We have panelists representing nonprofits focused on diversity in CS (NCWIT, CMD-IT, CRAW, BRAID), academic institutions committed to inclusivity (e.g., Colorado School of Mines, Cornell Tech, UCLA), and researchers studying ongoing diversity efforts (Drs. DuBow and Sax). This breadth offers the expertise to provide nuanced advice around important topics that have no single answer, such as the following questions:

- How should you allocate funds between student affinity groups, conference travel, and staff support for BPC?

- How do you help faculty connect BPC activities to research in $\mathrm{CS}$ that does not otherwise relate to education or BPC?

- $\quad$ Should faculty who are resistant to BPC be encouraged to participate in fundamentally different ways?

Is $\mathrm{K}-12$ outreach a distraction to creating within-institution culture change or an important dimension of BPC activity?

This panel addresses the topic of the NSF goal to help PIs "develop interest, skills, and activities in support of BPC at all levels." (NSF 17-110). 


\section{Panel Structure}

5 minutes: The moderator, Colleen Lewis, will provide a brief introduction to the NSF initiative.

20 minutes: Each panelist will have three minutes to introduce themselves, their organization, and up to two resources for BPC. 35 minutes: Panelists will answer a set of questions based upon the interest of attendees.

15 minutes: Each panelist will have about two minutes to offer final thoughts and recommendations.

\section{Panelists}

\subsection{Tracy Camp, Colorado School of Mines}

Tracy Camp is a Full Professor and Head of the Department of Computer Science at Colorado School of Mines. Dr. Camp is a former co-chair of the Committee on the Status of Women in Computing Research (CRA-W), and continues to be involved today on the CRA-W Board and CRA-W Steering Committee. CRA-W has a variety of programs for BPC seeking to support women at every level of the research pipeline: undergraduate students, graduate students, faculty, and industry and government researchers. Dr. Camp is also a member of the Steering Committee for BPC-net, which is a new NSF-sponsored repository of $\mathrm{BPC}$ resources.

\subsection{Wendy DuBow, NCWIT}

Wendy DuBow is the director of evaluation and a senior research scientist at the National Center for Women \& Information Technology (NCWIT). NCWIT exists to provide interested parties with research-backed techniques for increasing the meaningful participation of all girls and women in computing disciplines. We do through this sharing readable, professionally designed practical materials about how to recruit and retain underrepresented groups in computing. Because changing the status quo requires changing systems, not individuals, we encourage organizations to take a strategic, systemic approach to broadening participation in computing. DuBow will present NCWIT's strategic change model that enables faculty and administrators to identify which area(s) of change they will focus on and then supplies them with relevant practices (https://www.ncwit.org/recruit-and-retainstrategically). The six key focus areas for changing the environment for students are: recruiting, curriculum, pedagogy, supporting students, institutional policies, and evaluation.

\subsection{Diane Levitt, Cornell Tech}

Diane Levitt is the Senior Director of K-12 Education at Cornell Tech, the new graduate campus of Cornell University in New York City. She drives the campus engagement with the NYC computing education community, including the Dept. of Education's CS4All initiative, and works with individual schools to catalyze K-12 computer science, notably through the Teacher in Residence program which places CS master teachers as content coaches in public elementary and middle schools. Diane will present Cornell Tech's model for investing in K-12 computing education, wherein the campus acts as a hub for building the capacity of teachers to incorporate CS, involving faculty, graduate students and staff in these efforts. Levitt has been a panelist reviewing NSF BPC Plans. Some documentation of Cornell Tech's work can be found at:

- https://www.learntechlib.org/primary/p/181938/

- https://tech.cornell.edu/news/cornell-tech-programprepares-k-12-teachers-to-teach-computer-science/

- https://tech.cornell.edu/news/transforming-computerscience-education-in-public-schools/

\subsection{Linda J. Sax, UCLA}

Linda J. Sax is Professor of Higher Education in the Graduate School of Education \& Information Studies at UCLA. She is the Principal Investigator for the research component of the Building, Recruiting and Inclusion for Diversity (BRAID) initiative aimed at diversifying undergraduate computing. Dr. Sax will draw from interviews with computer science department chairs and surveys of computing students to discuss how BRAID institutions have engaged in BPC activities. She will also discuss the research methods used to study institutional adoption of BPC activities and their impact on students. Two key resources for this information are the BRAID website (https://braidresearch.gseis.ucla.edu/) and Dr. Sax's recentlypublished paper on the role of computer science department chairs in promoting gender and racial diversity (http://www.dl.begellhouse.com/journals/00551c876cc2f027,6110 65c054afe923,28d870d57ed75b8d.html).

\subsection{Valerie Taylor, CMD-IT}

Valerie Taylor is CEO and President of the Center for Minorities and People with Disabilities in IT (CMD-IT). CMD-IT offers a range of programs focused on professional development for students, faculty and professionals from the target groups. CMDIT also has reports documenting the participation of minorities and people with disabilities in computing (http://www.cmdit.org/resources/). These can be helpful resources for documenting patterns of underrepresentation. Additionally, these resources challenge the narrative that there are no minorities or people with disabilities in IT. CMD-IT is also the presenter of the Richard Tapia Celebration of Diversity in Computing Conferences (http://www.tapiaconference.org). Valerie Taylor is also the Director of the Mathematics and Computer Science Division at Argonne National Laboratory. Before joining Argonne in 2017, Dr. Taylor was on the faculty at Texas A\&M. Taylor is a fellow of both IEEE and ACM. She has received numerous awards, including the Richard A. Tapia Achievement Award for Scientific Scholarship. Civic Science, and Diversifying Computing.

\subsection{Colleen M. Lewis, CSTeachingTips.org}

The moderator, Colleen Lewis, is the McGregor-Girand Associate Professor of computer science at Harvey Mudd College. Lewis curates CSTeachingTips.org, a NSF-sponsored project for disseminating effective computer science teaching practices. For example, http://csteachingtips.org/tips-fordepartment-inclusivity provides tips for creating an inclusive department culture, which could inform department BPC plans. 